\title{
Factors Associated with Food Hygiene Practices Among Street Food Vendors in Padawan, Sarawak
}

\author{
DREND JORES*, MOHAMAD TAHA ARIF \& MD MIZANUR RAHMAN \\ ${ }^{1}$ Faculty of Medicine and Health Sciences, Universiti Malaysia Sarawak, 94300 Kota Samarahan, \\ Sarawak, Malaysia \\ *Corresponding author: princejowee@gmail.com
}

\begin{abstract}
The safety and quality of street foods are still questionable. Street food vendors are often poorly educated and untrained in food safety with lack of food safety knowledge and poor hygiene practice. This study aims to identify the factors associated with hygienic practice of food safety among the streets food vendors in Padawan district, Sarawak. This was a cross-sectional study conducted in Padawan, Sarawak. Data was collected by face to face interview using a validated structured questionnaire. The practice of food safety was observed using a structured observation checklist. Data entry and analysis was done by SPSS version 22.0. A p value $<0.05$ was considered as statistically significant. A total of 117 street food vendors were interviewed. The mean (SD) age was 41.0 (11.8) years. Three-fifths $(62.9 \%)$ of the respondents had secondary level of education and higher. The mean (SD) duration of vending was 7.2 (6.7) years. Only 35.9\% of the street food vendors received at least one training on food safety. Bivariate analysis revealed that religion, knowledge and attitude appeared to be statistically significant predictors of food safety and hygiene practice. However, multinomial regression analysis revealed that only religion appeared to be important predictor of food safety and hygiene practice (AOR $=14.730,95 \%$ CI: 1.267, 171.228). Although this study failed to establish a statistical significant association between knowledge and attitude with the hygiene practice due to inadequate sample size, some relationship does seem to exist, suggesting that food safety knowledge is vital for all street food vendors to have the necessary skills to enable them to handle food hygienically and ensure food sold is safe for consumption.
\end{abstract}

Keywords: Food safety, food vendors, hygiene practices, Malaysia, Sarawak

Copyright: This is an open access article distributed under the terms of the CC-BY-NC-SA (Creative Commons Attribution-NonCommercial-ShareAlike 4.0 International License) which permits unrestricted use, distribution, and reproduction in any medium, for non-commercial purposes, provided the original work of the author(s) is properly cited.

\section{INTRODUCTION}

Street food industries are vital for development of city and town in meeting the demand of food dwellers as well as contribute to the economics of the nation. The effect of urbanization has created increasing need of ready to eat food among the working people especially women with less time to prepare meals at home (Fellows \& Hilmi, 2011). This industry has helped to provide a chance for self-employment and opportunity to develop personal business skill, become a major source or increase incomes of vendors particularly women and provide urban dwellers with inexpensive, varied and nutritious indigenous meals (Njaya, 2014; WHO, 2010).

Street food refers to ready-to-eat foods and beverages prepared and/or sold by vendors and hawkers especially in streets and other similar public places without further processing or preparation (WHO, 1996). They are cheaper, easily accessible, and often nutritious food for urban and rural poor and at the same time contribute to tourism industry (WHO, 1996). There are many different kinds of street food vendors, including those at fixed kiosks and mobile stands, those who sell from vehicles (carts, bicycles, trucks, etc.) or from plastic or cloths set out on the street, and street hawkers (FAO, 2007). Street food are prepared in informal manner in different setting either in small-scale food factories or traditional workshops, home, market or in the street itself (WHO, 2010). They may be prepared either without any preparation, ready to eat food or food cooked on the site (WHO, 1996).

Street food vending plays a significant role in the economy of developed and developing countries, however, the safety and quality of the street foods are still questionable. The risk of food poisoning resulting from street vended food remains a threat in many parts of the world (FAO, 2009). The poor environmental condition in which the street foods are being prepared or 
sold often considered as unhygienic and low in quality in addition to lack of adequate knowledge on food preparation and handling by the food vendor themselves (Annan-Prah et al., 2011; Rane, 2011). Various studies has shown that most of the street food vendors have poor hygiene practices (Andy et al., 2015; Lalit et al., 2015). Several factors leading to poor food safety and hygiene practices have been identified including lack of food safety knowledge, poor attitude towards food safety, and education level (Cuprasitrut et al., 2011; Mulugeta \& Bayeh, 2012; Afolaranmi et al., 2015; Mohd. Firdaus Siau et al., 2015).

Street food vending is still a popular activity to meet the food demand of the growing population especially in Padawan District, Kuching. However, little is known about the nature of food safety and hygiene practices put in place by street food vendors as well as the factors affecting them to ensure food they sell are safe for consumption. Therefore, this study aimed to identify the factors and to assess the hygienic practices of street food vendors in relation to food safety.

\section{MATERIALS AND METHODS}

\section{Study Design and Sampling Procedure}

This was a cross-sectional study conducted in selected areas of Padawan District. The survey was conducted from February 2017 to April 2017. Sample size was calculated based on the proportion of street food vendors in previous studies in Malaysia (Rahman et al., 2012). The required sample size was 302 with 5\% absolute precision and after considering a non-respondent rate of $10 \%$. However, a total of 117 food vendors were interviewed. A non-probability sampling technique was applied to select the respondents. The inclusion criteria included all the street food vendors who were 18 years and above registered under Padawan Municipal Council administration. Those who were deaf, and unwilling to participate were excluded from the study.

\section{Instrument Development and Data Collection Procedure}

Data was collected by face-to-face interview using a validated structured questionnaire. Interview was conducted in English or Bahasa Malaysia (Malay language) depending on respondent preferences. The questionnaires used in this study was adopted from study by Rahman et al. (2012) in Northern Kuching City, Malaysia. The questionnaire was divided into five parts consisting of personal and socio-demographic characteristics, knowledge, attitude, practice and training on food safety. The first part was designed to determine the food handlers' sociodemographic characteristics including age, sex, educational background, ethnicity and duration of vending. The second part was on knowledge related to food safety and included nine questions. These questions covered general food safety knowledge such as personal hygiene, definition of food borne illness, time and temperature control, cross contamination, glove use, and sanitizing. Response to each item was assigned 'yes', 'no' or 'don't know'. One mark was given for correct answer; zero mark for those who gave incorrect answer or 'don't know'. Maximum mark would be nine and lowest would be zero. The third part of the questionnaire included 12 questions to determine the food handlers' attitudes toward food safety. A 5-point Likert type rating scale, ranging from zero (0) "no response" to four (4) "strongly agree", was used. Score of four was given for "strongly agree", three for "agree", two for "disagree", one for "strongly disagree" and zero for "no response or not applicable". Maximum mark would be 48 and minimum mark would be zero. The fourth part of the questionnaire consisted of 18 questions measuring vendors' self-reported onthe-job food safety and hygiene practices. A 3point rating scale was used to indicate frequency of food safety and hygiene practices: always; sometimes; and never. Score of two assigned for "always", one for "sometimes" and zero for "never". An option of "not applicable" was provided for each practice question. Highest mark would be 36 and lowest mark would be zero. To determine the level of food safety knowledge (Part Two), attitude (Part Three) and hygiene practice (Part Four), the scores in each part were ranked into three categories of having poor, average and good score based on one standard deviation (SD) from the mean with below one SD from mean as having poor level, above one SD from mean as having good level with the remaining as having average level. The last part of the questionnaire was developed to identify food safety topics taught to food handlers during orientation or on-the-job training, 
curriculum contents and others. Response to each item was 'yes' or 'no'. In addition, the food safety and hygiene practice of the vendors were observed by using the food safety observation checklist form. The food safety observation checklist was developed based on the vendors' self-reported on-the-job food safety practices. A total of 13 items were included in the observation checklist. The response for each item were either 'yes' or 'no' with option of 'not applicable'. The interviewer assessed whether food safety and hygiene practices were really put in place, for example, does the vendor uses a separate clean utensil for each food item as opposed to self-reported practices under the Food Safety and Hygiene Practices section in the questionnaires. Informed written consent was taken from each respondent. Ethical clearance (Ref: UNIMAS/NC-21.02/03-02 Jld.2(57)) was obtained from Universiti Malaysia Sarawak (UNIMAS).

\section{Data Processing and Analysis}

After the data collection, the questionnaires were being checked and verified for the completeness of all answered items before the data were entered into the computer. A total of 117 completed questionnaires were used for final analysis. The data were entered into the computer and coded to facilitate statistical analysis. The data were examined for any duplication or missing data. The analysis was carried out by Statistical Package for the Social Sciences (SPSS) 22.0 version. The numerical data were analysed using descriptive statistics to describe the sociodemographic characteristics of streets food vendors and determine the food safety knowledge, attitude and hygienic practices profile of street food vendors. For inferential analysis to determine the factors associated with food safety and hygiene practices, Chi-square Test of Independence was used for categorical variables while one-way Analysis of Variance (ANOVA) and Kruskal Wallis test were used for continuous variables. Subsequently, significant variables in Chi-square test, one-way ANOVA and Kruskal Wallis test were further analysed in Multinomial Logistic Regression (MLR). A $p$ value less than 0.05 was considered as statistically significant.

\section{RESULTS}

\section{Sociodemographic Characteristics}

Table 1 shows the summarized demographic profile of respondents. Out of the 117 respondents, $59.8 \%$ were female while $40.2 \%$

Table 1. Sociodemographic characteristics of the respondents.

\begin{tabular}{lcc}
\hline Characteristics & $\mathbf{n}(\%)$ & Mean (SD) \\
\hline Mean (SD) age in years & & \\
Gender & $47(40.2)$ \\
Male & $70(59.8)$ \\
Female & $9(7.7)$ \\
Education & $27(23.1)$ \\
$\quad$ No formal and incomplete primary education & $81(69.2)$ \\
Complete primary education & \\
Secondary education and above & $71(60.7)$ \\
Religion & $20(17.1)$ \\
Islam & $26(22.2)$ \\
Christianity & $69(59.0)$ \\
Buddhism & $35(29.9)$ \\
Ethnicity & $35(29.9)$ \\
Malay & $2(1.7)$ \\
Chinese & \\
Bidayuh & $115(98.3)$ \\
Others & $2(1.7)$ \\
Citizenship & \\
Malaysian & $24(20.5)$ \\
Non-Malaysian & $93(79.5)$ \\
Marital status & \\
Single & \\
Married & \\
Mean monthly income $($ RM) & \\
Mean duration of vending (years) & $42(35.9)$ \\
Training on food safety & $75(64.1)$ \\
Yes &
\end{tabular}


were males. The mean age (SD) of the respondents was 41.0 (11.8) years. More than two-thirds $(69.2 \%)$ of the respondents had secondary education and higher followed by primary education completed $(23.1 \%)$ and either no formal education or incomplete primary education (7.7\%). Most of the respondents were Muslim (60.7\%). In term of ethnicity, majority were Malay $(59.0 \%)$, followed by Chinese (29.9\%), Bidayuh $(9.4 \%)$ and others $(1.7 \%)$. Majority of the respondents were married (78.6\%). The mean (SD) duration of vending was 7.2 (6.7) years with $61.5 \%$ of them engaged in street food vending for 5 years and below. Only $35.9 \%$ of the street food vendors received at least one training on food safety.

\section{Food Safety Knowledge}

Table 2 shows food safety knowledge among the respondents in Padawan. The mean score of food safety knowledge was $6.1(\mathrm{SD}=1.7)$ with minimum score of 1.0 and maximum score of 9.0. A total of $20.5 \%$ of the respondents were having poor knowledge, $57.3 \%$ were average with the remaining $22.2 \%$ were having good knowledge. More than $96 \%$ of the respondents were able to answer the knowledge related to personal hygiene correctly. A high proportion of respondents were also able to answer the knowledge regarding food borne illnesses correctly $(93.2 \%)$. However, more than $50 \%$ of the respondents were unable to answer the knowledge related to time and temperature control. In term of cross contamination knowledge, $62.9 \%$ of the respondents were able to give the correct answer. $90.6 \%$ of the respondents were knowledgeable about sanitizer use.

\section{Food Safety Attitude}

Table 3 shows food safety attitude profile among the respondents in Padawan. Mean score of attitude towards food safety were $36.0(\mathrm{SD}=4.1)$ with minimum score of 22 and maximum score of $45.12 .0 \%$ of the respondents were having poor attitude, $72.6 \%$ were average while $15.4 \%$ of them were having good attitude. All the respondents agreed that sanitation is an important part of their job responsibilities and will select a place to eat based on its reputation for good sanitation and cleanliness. There were $2.6 \%$ respondents who think that it is important to have tasty food rather than safe food. One tenth $(10.3 \%)$ of the respondents were uncertain to obtain more knowledge regarding food safety and to attend food safety training course. Another one third $(34.2 \%)$ of the respondents agreed that only full-time employees should receive food safety training.

Table 2. Food safety knowledge among the respondents.

\begin{tabular}{|c|c|c|c|}
\hline \multirow[t]{2}{*}{ Statement } & \multicolumn{3}{|c|}{ Response, n (\%) } \\
\hline & Yes & No & Don't know \\
\hline $\begin{array}{l}\text { After washing hands, vendors should avoid touching their } \\
\text { hair. }\end{array}$ & $113(96.6)$ & $3(2.6)$ & $1(0.9)$ \\
\hline $\begin{array}{l}\text { The most important rule of food service personal hygiene } \\
\text { is that vendors must wash their hands often. }\end{array}$ & $116(99.1)$ & $1(0.9)$ & $0(0.0)$ \\
\hline $\begin{array}{l}\text { Food borne illnesses are diseases that are carried or } \\
\text { transmitted to people by food. }\end{array}$ & $109(93.2)$ & $4(3.4)$ & $4(3.4)$ \\
\hline $\begin{array}{l}\text { The most important factors to control the growth of } \\
\text { bacteria are temperature and time. }\end{array}$ & $70(59.8)$ & $8(6.8)$ & $39(33.3)$ \\
\hline $\begin{array}{l}\text { When holding hot foods for service, it is required that } \\
\text { internal food temperatures be taken at least every two } \\
\text { hours. }\end{array}$ & $35(29.9)$ & $39(33.3)$ & $43(36.8)$ \\
\hline $\begin{array}{l}\text { The temperature danger zone for potentially hazardous } \\
\text { foods is } 5^{\circ} \text { to } 60^{\circ} \mathrm{C} \text {. }\end{array}$ & $40(34.2)$ & $26(22.2)$ & $51(43.6)$ \\
\hline $\begin{array}{l}\text { Under running water that is } 21^{\circ} \mathrm{C} \text { or less is an acceptable } \\
\text { method for thawing frozen food. }\end{array}$ & $39(33.3)$ & $39(33.3)$ & $39(33.3)$ \\
\hline $\begin{array}{l}\text { Cross contamination is the transfer of harmful substances } \\
\text { or micro-organisms to food from food or from a non-food- } \\
\text { contact surface, such as equipment, utensils, or hands. }\end{array}$ & $81(69.2)$ & $25(21.4)$ & $11(9.4)$ \\
\hline $\begin{array}{l}\text { When sanitizers are use, the contact period must be } 30-60 \\
\text { seconds. }\end{array}$ & $106(90.6)$ & $7(6.0)$ & $4(3.4)$ \\
\hline
\end{tabular}


Table 3. Food safety attitude among the respondents.

\begin{tabular}{|c|c|c|c|c|c|}
\hline \multirow[t]{2}{*}{ Statement } & \multicolumn{5}{|c|}{ Response, n (\%) } \\
\hline & SA & $\mathbf{A}$ & D & SD & NA \\
\hline $\begin{array}{l}\text { I think sanitation is an important part of my job } \\
\text { responsibilities. }\end{array}$ & $35(29.9)$ & $82(70.1)$ & $0(0.0)$ & $0(0.0)$ & $0(0.0)$ \\
\hline $\begin{array}{l}\text { I believe that good employee hygiene can prevent } \\
\text { foodborne illness. }\end{array}$ & $32(27.4)$ & $80(68.4)$ & $4(3.4)$ & $0(0.0)$ & $1(0.9)$ \\
\hline $\begin{array}{l}\text { I think that it is the responsibility of all food handlers } \\
\text { to ensure that food is safe to serve. }\end{array}$ & $19(16.2)$ & $96(82.1)$ & $2(1.7)$ & $0(0.0)$ & $0(0.0)$ \\
\hline $\begin{array}{l}\text { I am willing to change my food handling behaviours } \\
\text { when I know they are incorrect. }\end{array}$ & $8(6.8)$ & $104(88.9)$ & $2(1.7)$ & $0(0.0)$ & $3(2.6)$ \\
\hline I am willing to obtain more food safety knowledge. & $7(6.0)$ & $97(82.9)$ & $1(0.9)$ & $0(0.0)$ & $12(10.3)$ \\
\hline $\begin{array}{l}\text { It is more important to have tasty food rather than } \\
\text { safe food }{ }^{a} \text {. }\end{array}$ & $0(0.0)$ & $3(2.6)$ & $90(76.9)$ & $20(17.1)$ & $4(3.4)$ \\
\hline $\begin{array}{l}\text { I select a place to eat based on its reputation for good } \\
\text { sanitation and cleanliness. }\end{array}$ & $39(33.3)$ & $78(66.7)$ & $0(0.0)$ & $0(0.0)$ & $0(0.0)$ \\
\hline $\begin{array}{l}\text { I think that managers should educate employees on } \\
\text { personal hygiene and sanitation regularly. }\end{array}$ & $9(7.7)$ & $107(91.5)$ & $0(0.0)$ & $0(0.0)$ & $1(0.9)$ \\
\hline $\begin{array}{l}\text { I think that only full-time employees should receive } \\
\text { food safety training }{ }^{a} \text {. }\end{array}$ & $0(0.0)$ & $40(34.2)$ & $65(55.6)$ & $0(0.0)$ & $12(10.3)$ \\
\hline $\begin{array}{l}\text { I believe that food safety knowledge not only benefits } \\
\text { my work but also my personal life. }\end{array}$ & $17(14.5)$ & $93(79.5)$ & $2(1.7)$ & $0(0.0)$ & $5(4.3)$ \\
\hline I am willing to attend a food safety training course. & $8(6.8)$ & $97(82.9)$ & $0(0.0)$ & $0(0.0)$ & $12(10.3)$ \\
\hline $\begin{array}{l}\text { I believe that food safety knowledge would make me } \\
\text { more confident about my work. }\end{array}$ & $12(10.3)$ & $100(85.5)$ & $1(0.9)$ & $0(0.0)$ & $4(3.4)$ \\
\hline
\end{tabular}

Notes: $\mathrm{SA}=$ Strongly Agree; $\mathrm{A}=$ Agree; $\mathrm{D}=$ Disagree; $\mathrm{SD}=$ Strongly disagree; NA=Not applicable; ${ }^{a}=$ reverse scoring.

\section{Food Safety and Hygiene Practices}

Table 4 shows food safety and hygiene practices profile among the respondents in Padawan. Mean score of food safety and hygiene practices was $25.0(\mathrm{SD}=2.0)$ with minimum score of 20 and maximum score of $28.14 .5 \%$ of respondents were noted to have poor practice, $77.8 \%$ were having average practice and only $7.7 \%$ were having good practice. There were $19.7 \%$ of them reported that they never wear a hair restraint when working in food service.

Table 4. Food safety and hygiene practices among the respondents in Padawan.

\begin{tabular}{|c|c|c|c|c|}
\hline \multirow[t]{2}{*}{ Statement } & \multicolumn{4}{|c|}{ Response, n (\%) } \\
\hline & Always & Sometimes & Never & NA \\
\hline I use gloves or utensils to handle food that is ready-to-eat. & $93(79.5)$ & $24(20.5)$ & $0(0.0)$ & $0(0.0)$ \\
\hline I use a separate clean utensil for each food item. & $72(61.5)$ & $45(38.5)$ & $0(0.0)$ & $0(0.0)$ \\
\hline $\begin{array}{l}\text { I wash my hands vigorously with soap and water before } \\
\text { working with food. }\end{array}$ & $84(71.8)$ & $33(28.2)$ & $0(0.0)$ & $0(0.0)$ \\
\hline I wash raw foods before using it. & $115(98.3)$ & $2(1.7)$ & $0(0.0)$ & $0(0.0)$ \\
\hline I store chemicals in a non-food storage room. & $98(83.8)$ & $16(13.7)$ & $1(0.9)$ & $2(1.7)$ \\
\hline I store raw food items in an area separate from cooked food. & $111(94.9)$ & $5(4.3)$ & $0(0.0)$ & $1(0.9)$ \\
\hline I wear a clean uniform, when I work in food service. & $116(99.1)$ & $1(0.9)$ & $0(0.0)$ & $0(0.0)$ \\
\hline $\begin{array}{l}\text { I wear a hair restraint (cap or hairnet), when I work in food } \\
\text { service. }\end{array}$ & 35 (29.9) & $44(37.6)$ & $23(19.7)$ & $15(12.8)$ \\
\hline $\begin{array}{l}\text { I wash my hands and change into a new pair of gloves after } \\
\text { touching anything that may contaminate my hands, when I } \\
\text { prepare or serve food. }\end{array}$ & $70(59.8)$ & $46(39.3)$ & $1(0.9)$ & $0(0.0)$ \\
\hline I drink or eat food while I am serving or preparing food ${ }^{a}$. & $1(0.9)$ & $11(9.4)$ & $105(89.7)$ & $0(0.0)$ \\
\hline I clean and sanitize work surfaces after each task. & $116(99.1)$ & $1(0.9)$ & $0(0.0)$ & $0(0.0)$ \\
\hline $\begin{array}{l}\text { When I am in doubt about the safety of a previously cooked } \\
\text { food, I discard it. }\end{array}$ & $113(96.6)$ & $3(2.6)$ & $0(0.0)$ & $1(0.9)$ \\
\hline $\begin{array}{l}\text { I pay attention to expiration dates on foods and do not use } \\
\text { foods that have passed the expiration date. }\end{array}$ & $101(86.3)$ & $12(10.3)$ & $3(2.6)$ & $1(0.9)$ \\
\hline I use sanitizing after washing the pot and pan sink. & $100(85.5)$ & $17(14.5)$ & $0(0.0)$ & $0(0.0)$ \\
\hline
\end{tabular}

Notes: NA=Not Applicable; ${ }^{a}=$ reverse scoring. 
Factors Affecting the Food Safety and Hygiene Practices: Bi-variate Analysis

Chi-square Test of Independence was done to determine the association between the food safety and hygiene practices with sociodemographic characteristics, knowledge and attitude of the respondents (Table 5). A significant association was found between the food safety and hygiene practices with the religion, knowledge and attitude of the respondents $(p<0.05)$. However, the analysis did not find any significant association between age, gender, education level, ethnicity, family size, and monthly income, duration of vending and training with the food safety and hygiene practices of the respondents ( $p>0.05)$.

Table 5. Factors affecting food safety and hygiene practices: Bi-variate analysis.

\begin{tabular}{|c|c|c|c|c|c|}
\hline \multirow[t]{2}{*}{ Characteristics } & \multirow[t]{2}{*}{$\mathbf{n}$} & \multicolumn{3}{|c|}{ Level of practice } & \multirow[t]{2}{*}{ p-value } \\
\hline & & $\begin{array}{c}\text { Poor } \\
\% \text { / Mean }\end{array}$ & $\begin{array}{l}\text { Average } \\
\% \text { / Mean }\end{array}$ & $\begin{array}{c}\text { Good } \\
\% \text { / Mean }\end{array}$ & \\
\hline Mean (SD) age in years & 117 & $44.6(14.1)$ & $40.3(11.3)$ & $40.7(12.4)$ & $0.394^{\mathrm{a}}$ \\
\hline \multicolumn{6}{|l|}{ Gender } \\
\hline Female & 70 & 10.2 & 75.7 & 8.6 & \multirow[t]{2}{*}{$0.803^{\mathrm{b}}$} \\
\hline Male & 47 & 6.8 & 80.9 & 6.4 & \\
\hline \multicolumn{6}{|l|}{ Education level } \\
\hline No formal and incomplete primary education & 9 & 22.2 & 66.7 & 11.1 & \multirow[t]{3}{*}{$0.758^{\mathrm{b}}$} \\
\hline Complete primary education & 27 & 18.5 & 77.8 & 3.7 & \\
\hline Secondary education and above & 81 & 12.3 & 79.0 & 8.6 & \\
\hline \multicolumn{6}{|l|}{ Religion } \\
\hline Muslim & 71 & 8.5 & 80.3 & 11.3 & \multirow[t]{2}{*}{$* 0.021^{b}$} \\
\hline Non-Muslim & 46 & 23.9 & 73.9 & 2.2 & \\
\hline \multicolumn{6}{|l|}{ Ethnicity } \\
\hline Malay & 69 & 8.7 & 81.2 & 10.1 & \multirow[t]{2}{*}{$0.064^{\mathrm{b}}$} \\
\hline Non-Malay & 48 & 22.9 & 72.9 & 4.2 & \\
\hline Median family size & & 4.0 & 5.0 & 5.0 & $0.092^{\mathrm{c}}$ \\
\hline \multicolumn{6}{|l|}{ Marital status } \\
\hline Single & 24 & 12.5 & 79.2 & 8.3 & \multirow[t]{2}{*}{$0.947^{\mathrm{b}}$} \\
\hline Married & 93 & 15.1 & 77.4 & 7.5 & \\
\hline Median monthly income (RM) & 117 & 1000.0 & 1200.0 & 1000.0 & $0.132^{\mathrm{c}}$ \\
\hline Median duration of vending (years) & 117 & 5.0 & 5.0 & 6.0 & $0.634^{\mathrm{c}}$ \\
\hline \multicolumn{6}{|l|}{ Training received } \\
\hline Yes & 42 & 9.5 & 76.2 & 14.3 & \multirow[t]{2}{*}{$0.088^{\mathrm{b}}$} \\
\hline No & 75 & 17.3 & 78.7 & 4.0 & \\
\hline \multicolumn{6}{|l|}{ Level of knowledge } \\
\hline Poor & 24 & 33.3 & 62.5 & 4.2 & \multirow[t]{3}{*}{$* 0.040^{b}$} \\
\hline Average & 67 & 11.9 & 80.6 & 7.5 & \\
\hline Good & 26 & 3.8 & 84.6 & 11.5 & \\
\hline \multicolumn{6}{|l|}{ Level of attitude } \\
\hline Poor & 14 & 42.9 & 50.0 & 7.1 & \multirow[t]{3}{*}{$* 0.020^{b}$} \\
\hline Average & 91 & 12.1 & 80.2 & 7.7 & \\
\hline Good & 12 & 0.0 & 91.7 & 8.3 & \\
\hline
\end{tabular}

Factors Affecting Food Safety and Hygiene Practices: Multinomial Regression Analysis

Multinomial logistic regression analysis was done to determine the factors influencing the food safety and hygiene practices among the respondents (Table 6). Only predictor variables with $\mathrm{p}$-value $<0.05$ in Chi-square Test were entered into multivariate analysis. The dependent variables, the practice were polychotomous, and coded into poor (1), average (2) and good (3) in which poor was considered as reference category.

Food safety and hygiene practices was found to be associated with religion, knowledge and attitude level of the respondents in the Chi-square analysis (Table 2). The full model was statistically significant with $\chi^{2}(\mathrm{df})=20.116$ (10), $p<0.05$ indicating that the model was able 
to differentiate between respondents with poor, average and good practice. The goodness of fit indices was not statistically significant $(p>0.05)$ which indicated a good fitted model. During the analysis, only religion was found to be the important factor for good practices in food safety among the respondents. However, no other variables were significantly associated with the food safety and hygiene practices. The analysis revealed that Muslim had an odds ratio of 2.690, indicating that they were 2.690 more likely to have good practices.

Table 6. Factors affecting the food safety and hygiene practices: Multinomial regression analysis.

\begin{tabular}{|c|c|c|c|c|c|c|}
\hline \multirow[t]{2}{*}{ Variables } & \multicolumn{3}{|c|}{ Average } & \multicolumn{3}{|c|}{ Good } \\
\hline & $\beta$ & Adj OR & $95 \% \mathrm{CI}$ & $\beta$ & Adj OR & $95 \% \mathrm{CI}$ \\
\hline Intercept & \multicolumn{3}{|c|}{$2.352 *$} & \multicolumn{3}{|c|}{-1.393} \\
\hline \multicolumn{7}{|l|}{ Religion } \\
\hline $\begin{array}{l}\text { Muslim } \\
\text { Non-muslim (RC) }\end{array}$ & 1.054 & $\begin{array}{c}2.869 \\
1\end{array}$ & $0.899,9.156$ & $* 2.690$ & $\begin{array}{c}14.730 \\
1\end{array}$ & $1.267,171.228$ \\
\hline \multicolumn{7}{|l|}{ Knowledge level } \\
\hline Poor & -2.081 & 0.125 & $0.010,1.634$ & -3.778 & 0.230 & $0.000,1.565$ \\
\hline Average & -1.373 & 0.253 & $0.25,2.610$ & -1.703 & 0.182 & $0.011,2.896$ \\
\hline Good (RC) & & 1 & & & 1 & \\
\hline \multicolumn{7}{|l|}{ Attitude level } \\
\hline Poor & -0.796 & 0.451 & $0.042,4.855$ & 1.314 & 3.722 & $0.041,338.719$ \\
\hline Average & 0.563 & 1.756 & $0.273,11.316$ & 1.039 & 2.825 & $0.157,50.935$ \\
\hline Good (RC) & & 1 & & & 1 & \\
\hline
\end{tabular}

Notes: RC=Reference category, Dependent variable is level of practice (Poor as RC, Moderate, Good); Model Chi square $\chi^{2}$ (df): 20.116 (10), $p<0.05$; Goodness of fit Chi square $\chi 2$ (df): 15.153 (16), $p>0.05 ; * p<0.05 ; * * p<0.01 ; * * * p<0.001$.

\section{DISCUSSION}

Only religion was found to be significantly associated factor with food safety and hygiene practices among street food vendors in Padawan. The analysis did not find any significant relationship between the other sociodemographic factors such as duration of vending, training, level of knowledge and attitude towards food safety with the food safety and hygiene practices of the vendors. It was found that Muslim vendors has a better food safety and hygiene practices $(\mathrm{AOR}=14.730$, 95\% CI: 1.267-171.228). This finding suggests that the chance of getting good food safety and hygiene practices among food vendors is highest among Muslim food vendors. However, this might be due to the fact that the food vendors in Padawan are predominantly Muslim. Although bivariate analysis revealed that knowledge and attitude were significantly associated with food safety and hygiene practices, the multivariate analysis did not establish any significant relationship between knowledge and attitude with the food safety and hygiene practices of the food vendors. This suggests that both knowledge and attitude towards food safety did not have influence upon the food safety and hygiene practices when the effects of other variables are controlled.
Training is fundamentally important to any food safety and hygiene system. According to WHO-FAO(UN) (2009), those engaged in food operations who come directly or indirectly into contact with food should have the necessary knowledge and skills to enable them to handle food hygienically. However, this study did not show any significant association between training and food safety and hygiene practices of the street food vendors. This contradicts the studies done in Nigeria (Afolaranmi et al., 2015; Andy et al., 2015), Ghana (Monney et al., 2014), Ethiopia (Mulugeta \& Bayeh, 2012), Philippines (Calopez et al., 2017) and Malaysia (Rahman et al., 2012) in which food safety training was significantly associated with the food safety and hygienic practices. This might be due to the fact that more than two thirds of the street food vendors in Padawan did not received any formal training on food safety. This indicated that food safety training among the street food vendor in Padawan did not have impact towards the hygienic practices. This can be supported by the regression analysis which revealed that the knowledge usually acquired through training itself did not significantly associated with the food safety and hygiene practice of the vendors. Egan et al. (2007) suggest that food safety training should be conducted at the workplace 
with increased training hours, which would result in improvements in food safety and hygiene practices, and that effective food hygiene training needs to target changing the behaviors of street vendors with constant evaluation.

The regulation of food safety in Malaysia is governed by the Food Safety and Quality Division, The Ministry of Health Malaysia under the Food Act 1983, Food Regulation 1985 and Food Hygiene Regulation 2009. The latest Food Hygiene Regulation 2009 provides an infrastructure to control the hygiene and safety of food sold to protect the public health. The areas of regulation include personal hygiene and practice of food handlers and food premises, clean and suitable utensils and equipment, as well as enforcement activities in food premises including those conducted by the Local Authorities. The implementation of latest Food Hygiene Regulation 2009 is important to ensure food premises are clean, sanitary and consumers can consume food that are clean and safe at a reasonable price.

The licensing of street vendors in Malaysia is under the jurisdiction of local council. Local council are responsible in the regulation of food safety among the street food vendors. The areas of regulation are similar as those under the jurisdiction of Food Safety and Quality Division, Ministry of Health Malaysia including providing training to the food vendors. Both Food Act 1983 and Food Hygiene Regulations 2009 serve as the overall reference for street food vending. Section 2 of the Food Act 1983 stated that "food premises" can include any street, open space or place of public resort or bicycle or any vehicle used for or in connection with the preparation, preservation, packaging, storage, conveyance, distribution or sale of any food while Section 3 of Food Hygiene Regulations 2009 require all the food premises including street food vendors to be registered. Section 30 of Food Hygiene Regulations 2009 require all food handlers including street food vendors to be trained and obtain a Certificate of Food Handlers Training. With such requirement, all the food vendors should be registered, trained and certified in food safety before working in food services.

Education has been reported to play a key role in increasing the food safety knowledge of food vendors, thus improving their attitudes towards food safety and hygiene (WHO, 1996). Several studies also has shown the association between educational level and the food safety and hygiene practices (Lawan et al., 2015). However, current study implies that the level of education has no effect on the practice of food hygiene by the food vendors. One of the possible reason is since food preparation and handling can be learnt informally, acquiring higher qualifications may not have appreciable effect on the outcome of food preparation and handling. Although majority of the vendors were female, there was no significant difference in the food safety and hygiene practices among male and female vendors in Padawan. Such findings were also seen in other study in which gender was not the factor associated with food safety and hygiene practices (Samapundo et al., 2016). Even though women are traditionally involved in food preparation at home while men are away at work, the finding in this study could support that the experience may not determine the practice which might differ at home and during working in food service.

A major limitation in this study was the inability to achieve the required sample size. The inclusion criteria that restrict the respondents selected must be from those registered under local council making it impossible to meet the required sample size. In such condition, all the samples were purposively selected which may not ensure the representativeness of the street food vendors and thus lead to bias. The observation of food safety and hygiene practices can lead to observer bias. To minimise the observer bias, only one observer was assigned to observe the practice and the observation was based on the same observation checklist that used for all food premises.

\section{CONCLUSION}

Although this study was not able to establish a statistical significant association between knowledge and attitude with the food safety and hygiene practices, some relationship does seem to exist. Knowledge which acquired through training is essential in food safety as it is shown to increase food handler's knowledge of proper food safety and hygiene practices (Park et al., 2010; Afolaranmi et al., 2014). Thus, continuous training is vital for all street food vendors to have the necessary knowledge and skills to enable them to handle food hygienically and ensure food sold is safe for consumption. 


\section{ACKNOWLEDGEMENTS}

We thank the Padawan Municipal Council and food vendors who agreed to participate in the study.

\section{REFERENCES}

Afolaranmi, T.O., Hassan, Z.I., Bello, D.A. \& Misari, Z. (2015). Knowledge and practice of food safety and hygiene among food vendors in primary schools in Jos, Plateau. Journal of Medical Research, 4(2): 16-22.

Afolaranmi, T.O., Hassan, Z.I., Bello, D.A., Tagurum, Y.O., Miner, C.A., Zoakah, A.I. \& Ogbonna, C. (2014). Training: a vital tool for improving the knowledge and practice of food safety and hygiene among food handlers in boarding secondary schools in Plateau State. Journal of Medicine in the Tropics, 16(2): 87-92.

Andy, E., Mangai, J.M., Kayong, E.A., Afoi, B.B., Goshit, J.D., Kasang, N. \& Innocent, O. (2015). Assessment of practice of food safety and hygiene among food vendors within Jos North Local Government Area of Plateau State, Nigeria. International Journal of Medical and Health Research, 1(2): 83-86.

Annan-Prah, A., Amewowor, D.H.A.K., Amoono, S.E., Akorli, S.Y., Saka, E. \& Ndadi, H.A. (2011). Street foods: handling, hygiene and client expectations in a World Heritage Site Town, Cape Coast, Ghana. African Journal of Microbiology Research, 5(13): 1629-1634.

Calopez, C.G., Herbalega, C.M.L., Canonicato, C.J., Españo, M.F. \& Francisco, A.J.M. (2017). Food safety awareness and practices of street food vendors in Iloilo City. In Plaisent, M. \& Valenzuela, A.J. (Eds.), $2017 \quad C E B U$ International Conference on Studies in Arts, Social Sciences and Humanities (SASSH-17) January 26-27, 2017, Cebu (Philippines).

Cuprasitrut, T., Srisorrachatr, S. \& Malai, D. (2011). Food safety knowledge, attitude and practice of food handlers and microbiological and chemical food quality assessment of food for making merit for monks in Ratchathewi District, Bangkok. Asia Journal of Public Health, 2(1): 27-34.

Egan, M.B., Raats, M.M., Grubb, S.M., Eves, A., Lumbers, M.L., Dean, M.S. \& Adams, M.R. (2007). A review of food safety and food hygiene training studies in the commercial sector. Food Control, 18(10): 1180-1190.

FAO. (2007). Promises and challenges of the informal food sector in developing countries. Rome, Italy. Retrieved from http://www.fao.org/docrep/010/a1124e/a1124e00 .htm
FAO. (2009). Good hygienic practices in the preparation and sale of street foods in Africa: tools for training. Retrieved from http://www.fao.org/docrep/012/a0740e/a0740e00. htm

Fellows, P. \& Hilmi, M. (2011). FAO Diversification booklet number 18: Selling street and snack foods. Rome: Rural Infrastructure and Agro-Industries Division Food and Agriculture Organization of the United Nations.

Lalit, I., Brkti, G. \& Dejen, Y. (2015). Magnitude of hygienic practices and its associated factors of food handlers working in selected food and drinking establishments in Mekelle town, northern Ethiopia. International Food Research Journal, 22(6): 2650-2656.

Lawan, U.M., Iliyasu, Z., Abubakar, S., Gajida, A.U. \& Abdussalam, A. (2015). Personal and food hygiene practices of subsistence food vendors operating in Kano metropolis, northwestern Nigeria. International Journal of Medical Science and Public Health, 4(2): 214-221.

Mohd. Firdaus Siau, A., Son, R., Mohhiddin, O., Toh, P.S. \& Chai, L.C. (2015). Food court hygiene assessment and food safety knowledge, attitudes and practices of food handlers in Putrajaya. International Food Research Journal, 22(5): 1843-1854.

Monney, I., Agyei, D., Ewoenam, B.S., Priscilla, C. \& Nyaw, S. (2014). Food hygiene and safety practices among street food vendors: an assessment of compliance, institutional and legislative framework in Ghana. Food and Public Health, 4(6): 306-315.

Mulugeta, K. \& Bayeh, A. (2012). The sanitary conditions of food service establishments and food safety knowledge and practices of food handlers in Bahir Dar town. Ethiopian Journal of Health Science, 22(1): 27-35.

Njaya, T. (2014). Operations of street food vendors and their impact on sustainable urban life in high density suburbans of Harare, in Zimbabwe. Asian Journal of Economic Modelling, 2(1): 18-31.

Park, S., Kwak, T. \& Chang, H. (2010). Evaluation of the food safety training for food handlers in restaurant operations. Nutrition Research and Practice, 4(1): 58-68.

Rahman, M.M., Arif, M.T., Bakar, K. \& Tambi, Z. (2012). Food safety knowledge, attitude and hygiene practices among the street food vendors in Northern Kuching City, Sarawak. Borneo Science, 31: 95-103.

Rane, S. (2011). Street vended food in developing world: hazard analyses. Indian Journal of Microbiology, 51(1): 100-106. 
Samapundo, S., Thanh, T.C., Xhaferi, R. \& Devlieghere, F. (2016). Food safety knowledge, attitudes and practices of street food vendors and consumers in Ho Chi Minh city, Vietnam. Food Control, 70: 79-89.

WHO. (1996). Essential safety requirements for street-vended foods. Geneva: Food Safety Unit, Division of Food and Nutrition, World Health Organization. Retrieved from http://apps.who.int/iris/bitstream/10665/63265/1/ WHO_FNU_FOS_96.7.pdf
WHO. (2010). Basic steps to improve safety of streetvended food. INFOSAN Information Note.

WHO-FAO(UN). (2009). Codex alimentarius: food hygiene (Basic texts). Fourth Edition. Rome: Food and Agriculture Organization of the United Nations, World Health Organization. Retrieved from

ftp://ftp.fao.org/codex/Publications/Booklets/Hyg iene/FoodHygiene_2009e.pdf 